\title{
CORRIGENDUM
}

DOI: $10.3892 /$ ijo.2020.5149

\section{ANXA1-derived peptides suppress gastric and colon cancer cell growth by targeting EphA2 degradation}

JUAN FENG, TA XIAO, SHAN-SHAN LU, XIAO-PU HUNG, HONG YI, QIU-YAN HE, WEI HUANG, YAO-YUN TANG and ZHI-QIANG XIAO

Int J Oncol 57: 1203-1213, 2020; DOI: 10.3892/ijo.2020.5119

Following the publication of the above article, the authors have realized that one of the data panels featured in Fig. 5D was selected incorrectly. Specifically, the wrong image was selected for the A1 (28-30), HCT116 experiment. The authors have revisited their original sources to identify the correct data panel, and can confirm that the error arose unintentionally during the process of compiling the figure.

The correct version of Fig. 5, featuring corrected data panel for Fig. 5D, is shown on the next page. The authors confirm that this error did not affect the conclusions reported in this study, and are grateful to the Editor of International Journal of Oncology for allowing them the opportunity to publish this corrigendum. Furthermore, the authors apologize to the readership of the Journal for any inconvenience caused. 
A
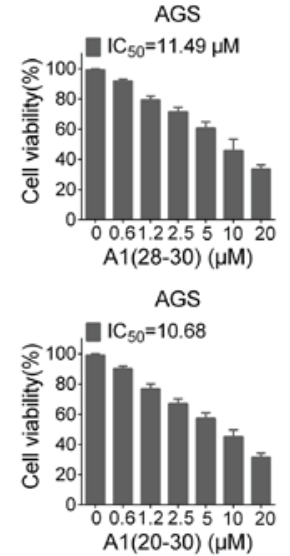

$\mathbf{B}$

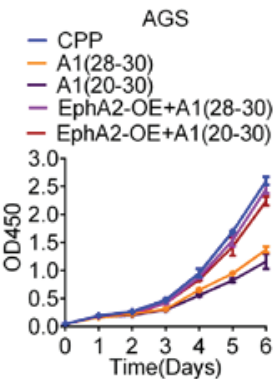

HCT116

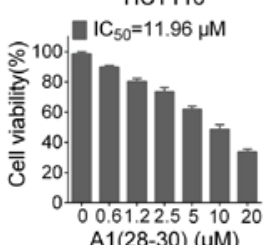

HCT116

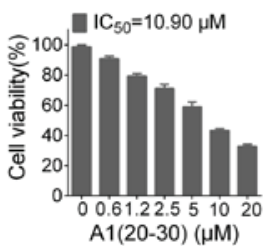

HCT116

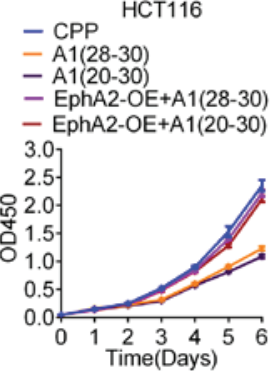

SW620

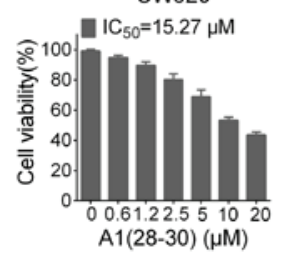

SW620

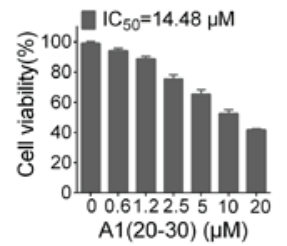

SW620

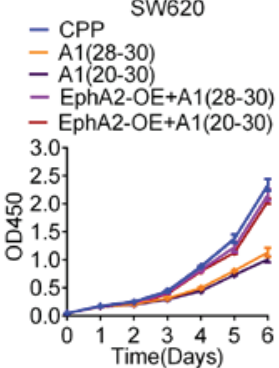

C
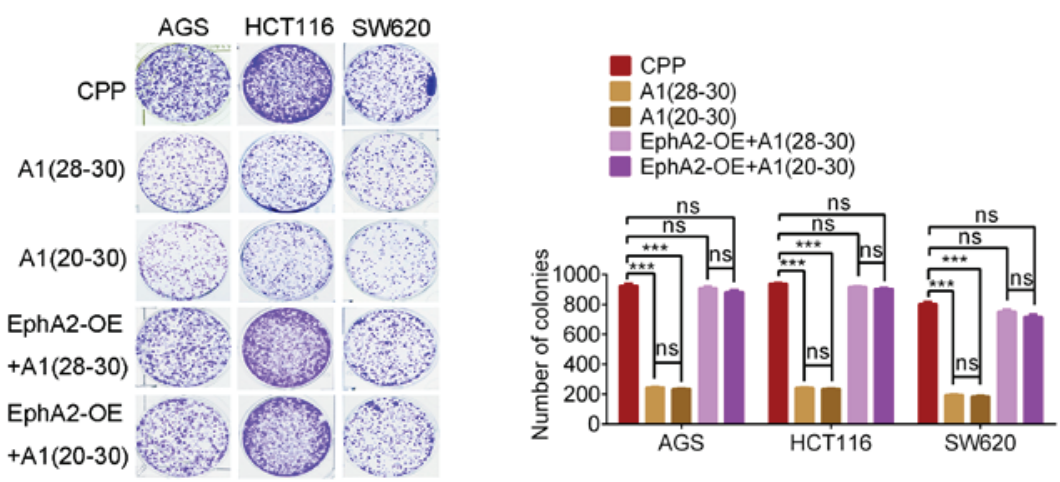

D
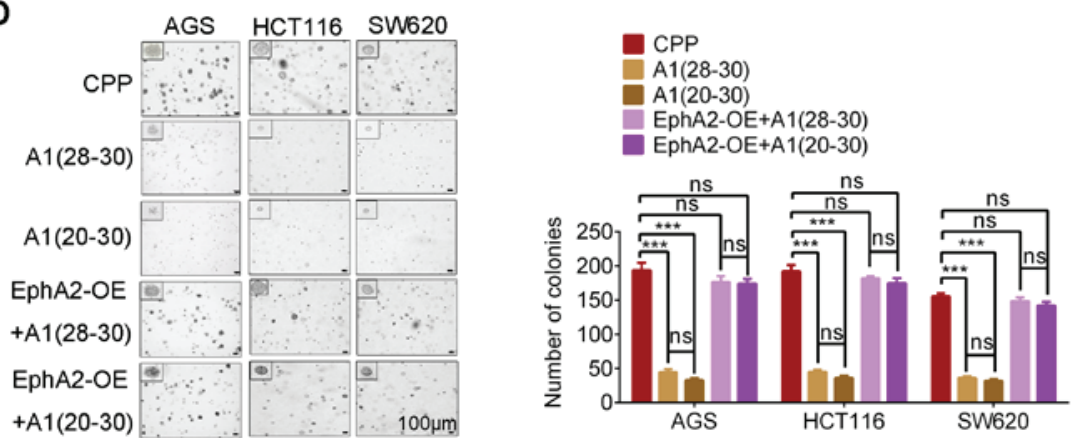

Figure 5. A1(28-30) and A1(20-30) possess anti-GC and anti-CC effect in vitro. (A) A1(28-30) and A1(20-30) decrease the viability of GC (AGS) and CC (HCT116 and SW620) cells. The cells were incubated with 0-20 $\mu \mathrm{M}$ peptides for $48 \mathrm{~h}$, and cell viability was measured by MTT assay. (B and C) A1(28-30) and A1(20-30) decrease the proliferation of GC (AGS) and CC (HCT116 and SW620) cells, and EphA2 overexpression rescues the effect of both peptides on the proliferation of GC and CC cells. The cells were incubated with $10 \mu \mathrm{M}$ peptides that was replenished every $24 \mathrm{~h}$, and cell proliferation was detected by CCK-8 (B) and plate colony formation (C) assay. (D) A1(28-30) and A1(20-30) decrease the anchorage-independent growth of GC (AGS) and CC (HCT116 and SW620) cells, and EphA2 overexpression rescues the effect of both peptides on the anchorage-independent growth of GC and CC cells. The cells were incubated with $10 \mu \mathrm{M}$ peptides that was replenished every $24 \mathrm{~h}$, and cell anchorage-independent growth was detected by soft agar colony formation assay. Representative images are shown on the left, and quantitative data are presented on the right. Scale bars, $100 \mu \mathrm{m}$. Error bars indicate means $\pm \mathrm{SD}$. ${ }^{* * *} \mathrm{P}<0.001$; ns, not significant as determined by Student's t-test. EphA2-OE, EphA2 overexpression; GC, gastric cancer; CC, colon cancer. 